\title{
GENERALISASI KETAKSAMAAN COSINUS PADA SEBARANG SEGITIGA
}

\author{
Nur Hidayatin ${ }^{1}$ \\ 1 FSAINTEK, Universitas PGRI Argopuro Jember \\ email korespondensi : hidayatin1990@gmail.com
}

\begin{abstract}
Diterima : (30-09-2021), Revisi: (17-11-2021), Diterbitkan : (05-12-2021)
ABSTRAK

Artikel ini membahas tentang ketaksamaan sinus dan cosinus pada sudut-sudut segitiga. Ketaksamaan ini meliputi ketaksamaan jumlahan sinus pada segitiga, ketaksamaan jumlahan sinus setengah sudut-sudut pada segitiga, ketaksamaan jumlahan cosinus pada segitiga, serta ketaksamaan perkalian cosinus yang berlaku pada sebarang segitiga. Sinus merupakan perbandingan sisi yang menghadap sudut dengan sisi miring pada segitiga, dan cosinus merupakan perbandingan sisi yang bersebelahan dengan sudut dengan sisi miring/ hipotenusa segitiga. Selain itu, juga digunakan aturan sinus dan cosinus, konsep segitiga meliputi jejari lingkaran dalam dan lingkaran luar segitiga, serta ketaksamaan rata-rata aritmatika dan geometri. Dengan menggunakan konsep-konsep segitiga dan sinus-cosinus tersebut, dapat diperoleh ketaksamaan cosinus yang berlaku pada segitiga. Dari ketaksamaan cosinus tersebut, dapat ditentukan generalisasi ketaksamaan jumlahan cosinus dan generalisasi ketaksamaan perkalian cosinus yang berlaku pada sebarang segitiga.

Kata kunci : ketaksamaan, cosinus, segitiga
\end{abstract}




\begin{abstract}
This article discusses the inequalities of sine and cosine of the angles of triangle. These inequalities include the inequalities of the sum of the sine of a triangle, the inequalities of the sum of sine of half the angles of the a triangle, the inequalities of the sum of the cosine in triangle, and the multiplication inequalitis of cosine that apply to any triangle. Sine is the ratio of the side opposite the angle to the hypotenuse of the triangle, and cosine is the ratio of the side opposite the angle to the hypotenuse of the triangle. In addition, the rules of sine and cosine are also used, the concept of a triangle includes the radius of the inner circle and outer circle of a triangle, as well as arithmatic and geometric mean inequalities. By using the concepts of triangles and sine-cosines, we can get the cosine inequalities that apply to triangels. From the cosine inequality, it can be determined the generalization of the cosine sum inequality and the generalization of the cosine multiplication inequality thet applies to any triangle.
\end{abstract}

Key words: inequality, cosine, triangle

\title{
Pendahuluan
}

Geometri merupakan cabang matematika yang mempelajari tentang pengukuran, bentuk-bentuk benda, baik bentuk benda alam maupun bentuk bangunan. Geometri merupakan salah satu bagian matematika yang sering ditemui dalam kehidupan sehari-hari. Sehingga sejak kecil anak anak sudah belajar mengenal bentuk-bentuk Geometri (Putri et al., 2020). Kumpulan titik-titik membentuk garis. Jika terdapat tiga garis yang tiap ujungnya saling bertemu sehingga membentuk sebuah bangun, maka bangun tersebut dinamakan segitiga. Segitiga merupakan bangun paling sederhana dari geometri. Segitiga dapat dimanfaatkan dalam menentukan panjang jari-jari lingkaran (Surlina et al., 2018). Ada banyak hal yang dapat dipelajari pada bidang segitiga, seperti garis-garis istimewa pada segitiga dan sudut-sudut segitiga (Kamariah, 2015). Selanjutnya daerah yang terbentuk dari pertemuan dua garis dinamakan sudut. Pada sebuah segitiga didapat tiga sudut seperti pada gambar berikut.

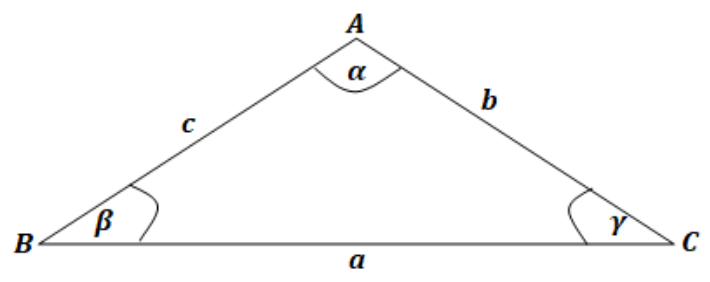

Gambar 1. Segitiga $A B C$ (Ayres, 1954) 
Berdasarkan gambar 1, diperoleh aturan sinus dan cosinus dengan menggunakan hukum Pythagoras yaitu

$$
\begin{aligned}
& \cos \alpha=\frac{b^{2}+c^{2}-a^{2}}{2 b c} \\
& \cos \beta=\frac{a^{2}+c^{2}-b^{2}}{2 a c} \\
& \cos \gamma=\frac{a^{2}+b^{2}-c^{2}}{2 a b}
\end{aligned}
$$

yang selanjutnya disebut aturan cosinus untuk sebarang segitiga (Hoehn, 2013).

Serta bentuk

$$
\frac{\sin \alpha}{a}=\frac{\sin \beta}{b}=\frac{\sin \gamma}{c}
$$

selanjutnya disebut aturan Sinus untuk sebarang segitiga (Coghetto, 2014).

Jika diberikan garis bagi sudut sehingga membagi dua sudut sama besar, maka diperoleh $0<\frac{\alpha}{2}, \frac{\beta}{2}, \frac{\gamma}{2}<\frac{\pi}{2}$ dan $\frac{\alpha}{2}+\frac{\beta}{2}+\frac{\gamma}{2}=\frac{\pi}{2}$, dengan $\alpha, \beta, \gamma$ merupakan sudut-sudut pada segitiga.

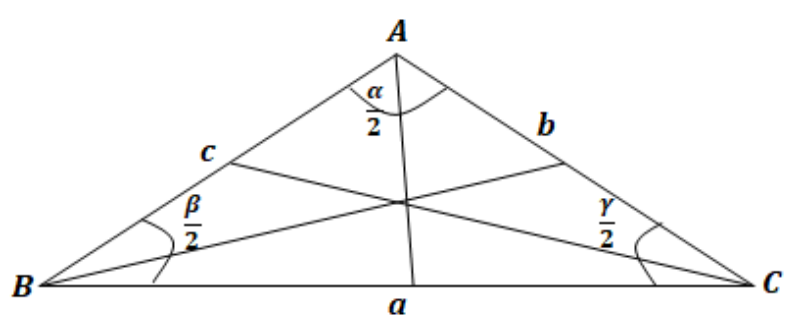

Gambar 2. Sudut Setengah

Dengan menggunakan aturan sinus dua sudut dan aturan cosinus (Conway \& Ryba, 2016), maka dapat diperoleh nilai sinus setengah sudut, yaitu

$$
\begin{aligned}
& \sin \left(\frac{\alpha}{2}\right)=\sqrt{\frac{(s-c)(s-b)}{b c}} \\
& \sin \left(\frac{\beta}{2}\right)=\sqrt{\frac{(s-a)(s-c)}{a c}} \\
& \sin \left(\frac{\gamma}{2}\right)=\sqrt{\frac{(s-a)(s-b)}{a b}}
\end{aligned}
$$

dengan $s$ menyatakan keliling pada segitiga (Chauvenet, 1887). Selanjutnya, diperoleh nilai cosinus setengah sudut sebagai berikut 


$$
\begin{aligned}
& \cos \left(\frac{\alpha}{2}\right)=\sqrt{\frac{s(s-a)}{b c}} \\
& \cos \left(\frac{\beta}{2}\right)=\sqrt{\frac{s(s-b)}{a c}} \\
& \cos \left(\frac{\gamma}{2}\right)=\sqrt{\frac{s(s-c)}{a b}}
\end{aligned}
$$

Dengan $s$ menyatakan keliling segitiga (Chauvenet, 1887).

\section{Metode Penelitian}

Penelitian ini merupakan penelitian kualitatif, dengan mengkaji pustaka suatu teori yang dikembangkan sehingga memunculkan generalisasi dari teori tersebut, yaitu generalisasi ketaksamaan cosinus pada sebarang segitiga. Untuk mendapatkan generalisasi dari ketaksamaan cosinus pada sebarang segitiga dilakukan beberapa langkah, yaitu : (1) mempelajari konsep trigonometri meliputi definisi sinus dan cosinus serta aturan sinus dan cosinus; (2) mengkaji/mempelajari konsep segitiga diantaranya hubungan jejari lingkaran dalam segitiga dengan sisi - sisi segitiga, dan hubungan jejari lingkaran luar segitiga dengan jejari lingkaran dalam segitiga, serta hubungan jejari tersebut dengan luas segitiga; (3) mengkaji ketaksamaan rata-rata aritmatika dan geometri; (4) mengkaji ketaksamaan sinus dan cosinus pada segitiga; (5) menentukan generalisasi dari ketaksamaan cosinus yang berlaku pada segitiga dan dibuktikan kebenarannya.

\section{Hasil dan Pembahasan}

Berdasarkan definisi sinus dan cosinus diatas, maka diperoleh beberapa ketaksaman trigonometri, khususnya ketaksamaan sinus dan cosinus pada segitiga yang tertuang pada beberapa teorema berikut.

Teorema 1. Diketahui $0<\alpha, \beta, \gamma<\pi$ dan $\alpha+\beta+\gamma=\pi$, berlaku $0<$ $\sin \left(\frac{\alpha}{2}\right) \sin \left(\frac{\beta}{2}\right) \sin \left(\frac{\gamma}{2}\right) \leq 1 / 8$ (Bottema, 1969).

Bukti. Dengan definisi sinus setengah sudut segitiga, diperoleh

$$
\sin \left(\frac{\alpha}{2}\right) \sin \left(\frac{\beta}{2}\right) \sin \left(\frac{\gamma}{2}\right)=\frac{(s-a)(s-b)(s-c)}{a b c}=\frac{L^{2}}{s a b c}
$$

dengan $L$ menyatakan luas pada sebarang segitiga, dan $s$ menyatakan keliling pada sebarang segitiga. Dengan menggunakan jejari lingkaran luar dan lingkaran 
dalam segitiga, yaitu $R=\frac{a b c}{4 L}$ dan $r=\frac{L}{s}, R$ merupakan jejari lingkaran luar segitiga dan $r$ dinotasikan sebagai jejari lingkaran dalam segitiga (Gonz, 2012; Josefsson, 2011), maka

$$
\sin \left(\frac{\alpha}{2}\right) \sin \left(\frac{\beta}{2}\right) \sin \left(\frac{\gamma}{2}\right)=\frac{L r}{4 R L}=\frac{r}{4 R}
$$

Karena $R \geq 2 r$ (Nhi, 2013), maka diperoleh

$$
\sin \left(\frac{\alpha}{2}\right) \sin \left(\frac{\beta}{2}\right) \sin \left(\frac{\gamma}{2}\right) \leq 1 / 8
$$

Selanjutnya karena $\alpha, \beta, \gamma>0$, sehingga mengakibatkan

$$
\sin \left(\frac{\alpha}{2}\right) \sin \left(\frac{\beta}{2}\right) \sin \left(\frac{\gamma}{2}\right)>0
$$

Teorema 2. Diketahui $0<\alpha, \beta, \gamma<\pi$ dan $\alpha+\beta+\gamma=\pi$, berlaku $\quad \frac{3}{4} \leq$ $\sin ^{2}\left(\frac{\alpha}{2}\right)+\sin ^{2}\left(\frac{\beta}{2}\right)+\sin ^{2}\left(\frac{\gamma}{2}\right)<1 \quad$ (Bottema, 1969).

Bukti. Dengan menggunakan identitas trigonometri (Sundstrom, Ted and Schlicker, 2021), diperoleh

$$
\sin ^{2}\left(\frac{\alpha}{2}\right)+\sin ^{2}\left(\frac{\beta}{2}\right)+\sin ^{2}\left(\frac{\gamma}{2}\right)=1-\left(\cos ^{2}\left(\frac{\alpha}{2}\right)-\sin ^{2}\left(\frac{\beta}{2}\right)-\sin ^{2}\left(\frac{\gamma}{2}\right)\right)
$$

Diperhatikan bahwa $\cos ^{2}\left(\frac{\alpha}{2}\right)-\sin ^{2}\left(\frac{\beta}{2}\right)-\sin ^{2}\left(\frac{\gamma}{2}\right)=\frac{1}{2} \cdot(\cos \alpha+\cos \beta)-\sin ^{2}\left(\frac{\gamma}{2}\right)$ (Gresham et al., 2019).

Dengan menggunakan definisi cosinus dua sudut (Beveridge, 2014), maka

$$
\begin{aligned}
\frac{1}{2}(\cos \alpha+\cos \beta)-\sin ^{2}\left(\frac{\gamma}{2}\right) & =\cos \left(\frac{\alpha+\beta}{2}\right) \cos \left(\frac{\alpha-\beta}{2}\right)-\sin ^{2}\left(\frac{\gamma}{2}\right) \\
& =2 \cdot \sin \left(\frac{\alpha}{2}\right) \sin \left(\frac{\beta}{2}\right) \sin \left(\frac{\gamma}{2}\right)
\end{aligned}
$$

Oleh karena itu, berdasarkan Teorema 1, diperoleh

$$
\frac{3}{4} \leq \sin ^{2}\left(\frac{\alpha}{2}\right)+\sin ^{2}\left(\frac{\beta}{2}\right)+\sin ^{2}\left(\frac{\gamma}{2}\right)<1
$$

Teorema 3. Diketahui $0<\alpha, \beta, \gamma<\pi$ dan $\alpha+\beta+\gamma=\pi$, berlaku $1<\cos \alpha+$ $\cos \beta+\cos \gamma \leq 3 / 2$ (Bottema, 1969).

Bukti. Diperhatikan bahwa $\cos \alpha+\cos \beta+\cos \gamma=-2 \cdot\left(\sin ^{2}\left(\frac{\alpha}{2}\right)+\sin ^{2}\left(\frac{\beta}{2}\right)+\right.$ 
$\left.\sin ^{2}\left(\frac{\gamma}{2}\right)\right)+3$ (Annaby \& Hassan, 2018).

Dengan menggunakan Teorema 2, diperoleh

$$
1<-2 \cdot\left(\sin ^{2}\left(\frac{\alpha}{2}\right)+\sin ^{2}\left(\frac{\beta}{2}\right)+\sin ^{2}\left(\frac{\gamma}{2}\right)\right)+3 \leq 3 / 2
$$

Teorema 4. Diketahui $0<\alpha, \beta, \gamma<\pi$ dan $\alpha+\beta+\gamma=\pi$, berlaku $0<$ $\cos \alpha \cos \beta \cos \gamma \leq 1 / 8$ (Bottema, 1969).

Bukti. Misalkan $x=\cos \alpha, y=\cos \beta$, dan $z=\cos \gamma$, dengan $0<\alpha, \beta, \gamma<\pi$. Berdasarkan ketaksamaan rerata aritmatika-geometri (Zou \& Jiang, 2015), didapat

$$
\left(\frac{\cos \alpha+\cos \beta+\cos \gamma}{3}\right)^{3} \geq \cos \alpha \cos \beta \cos \gamma
$$

Selanjutnya dengan memanfaatkan Teorema 3, diperoleh

$$
\cos \alpha \cos \beta \cos \gamma \leq 1 / 8
$$

Teorema 5. Diketahui $0<\alpha, \beta, \gamma<\pi$ dan $\alpha+\beta+\gamma=\pi$, berlaku $(\cos \alpha)^{2^{n}}+$ $(\cos \beta)^{2^{n}}+(\cos \gamma)^{2^{n}} \geq \frac{3}{(2)^{2^{n}}}$ pada setiap $n$ bilangan asli .

Bukti. Dengan memakai teknik induksi matematika,

(i) Misalkan untuk $n=1$, diperoleh $\cos ^{2} \alpha+\cos ^{2} \beta+\cos ^{2} \gamma=-\left(\sin ^{2} \alpha+\right.$ $\left.\sin ^{2} \beta+\sin ^{2} \gamma\right)+3 \geq 3 / 4$.

(ii) Diasumsikan benar untuk $n=k$, maka $(\cos \alpha)^{2^{k}}+(\cos \beta)^{2^{k}}+(\cos \gamma)^{2^{k}} \geq$ $\frac{3}{(2)^{2^{k}}}$.

(iii) Lebih lanjut, dibuktikan benar pada $n=k+1$, berlaku $(\cos \alpha)^{2^{k+1}}+$ $(\cos \beta)^{2^{k+1}}+(\cos \gamma)^{2^{k+1}} \geq \frac{3}{(2)^{2^{k+1}}}$.

Diketahui bahwa $\quad(\cos \alpha)^{2^{k+1}}+(\cos \beta)^{2^{k+1}}+(\cos \gamma)^{2^{k+1}}=\left(\cos ^{2^{k}} \alpha\right)^{2}+$ $\left(\cos ^{2^{k}} \beta\right)^{2}+\left(\cos ^{2^{k}} \gamma\right)^{2}$. Misalkan $a=\cos ^{2^{k}} \alpha, b=\cos ^{2^{k}} \beta, c=\cos ^{2^{k}} \gamma$, dengan $0<\alpha, \beta, \gamma<\pi$. Dengan memanfaatkan ketaksamaan dari kuadrat jumlahan panjang sisi segitiga (Mineno et al., 2012), diperoleh

$$
\left(\cos ^{2^{k}} \alpha\right)^{2}+\left(\cos ^{2^{k}} \beta\right)^{2}+\left(\cos ^{2^{k}} \gamma\right)^{2} \geq \frac{3}{(2)^{2^{k+1}}}
$$

Teorema 6. Diketahui $0<\alpha, \beta, \gamma<\pi$ dan $\alpha+\beta+\gamma=\pi$, sehingga berlaku 
$\cos \left(\frac{\alpha}{2^{n}}\right)+\cos \left(\frac{\beta}{2^{n}}\right)+\cos \left(\frac{\gamma}{2^{n}}\right) \leq \frac{3}{2} \cdot \sqrt{\frac{2+\sqrt{2+\sqrt{\cdots+\sqrt{2+1}}}}{\text { angka 2 sebanyaknsuku }}}$ untuk setiap $n$ bilangan bulat tak negatif.

Bukti. Dengan menggunakan induksi matematika,

(i) Untuk $n=0$, telah terbukti benar pada teorema 3

(ii) Diasumsikan benar untuk $n=k$, maka $\cos \left(\frac{\alpha}{2^{k}}\right)+\cos \left(\frac{\beta}{2^{k}}\right)+\cos \left(\frac{\gamma}{2^{k}}\right) \leq \frac{3}{2}$.

$$
\sqrt{\frac{2+\sqrt{2+\sqrt{\cdots+\sqrt{2+1}}}}{\text { angka 2 sebanyak k suku }}}
$$

(iii) Selanjutnya akan diuji kebenaran untuk $n=k+1$, berlaku $\cos \left(\frac{\alpha}{2^{k+1}}\right)+$

$$
\cos \left(\frac{\beta}{2^{k+1}}\right)+\cos \left(\frac{\gamma}{2^{k+1}}\right) \leq \frac{3}{2} \cdot \sqrt{\frac{2+\sqrt{2+\sqrt{\cdots+\sqrt{2+1}}}}{\text { angka 2 sebanyak } k+1 \text { suku }}}
$$

Diketahui bahwa

$$
\cos \left(\frac{\alpha}{2^{k+1}}\right)+\cos \left(\frac{\beta}{2^{k+1}}\right)+\cos \left(\frac{\gamma}{2^{k+1}}\right)=\sqrt{\frac{1+\cos \left(\frac{\alpha}{2^{k}}\right)}{2}}+\sqrt{\frac{1+\cos \left(\frac{\beta}{2^{k}}\right)}{2}}+\sqrt{\frac{1+\cos \left(\frac{\gamma}{2^{k}}\right)}{2}}
$$

Misalkan $x=\sqrt{\frac{1+\cos \frac{\alpha}{2^{k}}}{2}}, y=\sqrt{\frac{1+\cos \frac{\beta}{2^{k}}}{2}}, z=\sqrt{\frac{1+\cos \frac{\gamma}{2^{k}}}{2}}$. Dengan memanfaatkan ketaksamaan dari kuadrat jumlahan panjang sisi pada segitiga, diperoleh

$$
\sqrt{\frac{1+\cos \left(\frac{\alpha}{2^{k}}\right)}{2}}+\sqrt{\frac{1+\cos \left(\frac{\beta}{2^{k}}\right)}{2}}+\sqrt{\frac{1+\cos \left(\frac{\gamma}{2^{k}}\right)}{2}} \leq \frac{3}{2} \sqrt{\frac{2+\sqrt{2+\sqrt{\cdots+\sqrt{2+1}}}}{\text { angka 2 sebanyak } k+1 \text { suku }}}
$$

untuk setiap $\mathrm{n}$ bilangan bulat tak negatif.

Teorema 7. Diketahui $0<\alpha, \beta, \gamma<\pi \quad$ dan $\quad \alpha+\beta+\gamma=\pi$, berlaku $\cos \left(\frac{\alpha}{2^{n}}\right) \cos \left(\frac{\beta}{2^{n}}\right) \cos \left(\frac{\gamma}{2^{n}}\right) \leq \frac{(\underbrace{2+\sqrt{2+\sqrt{\cdots+\sqrt{2+1}}}}_{\text {angka2 sebanyakn suku }})^{\frac{3}{2}}}{8}$, untuk setiap $n$ bilangan bulat 
tak negatif.

Bukti. Dengan menggunakan induksi matematika,

(i) Untuk $n=0$, telah dibuktikan benar pada Teorema 4 .

(ii) Diasumsikan benar untuk $n=k$, maka $\cos \left(\frac{\alpha}{2^{k}}\right) \cos \left(\frac{\beta}{2^{k}}\right) \cos \left(\frac{\gamma}{2^{k}}\right) \leq$

$$
\frac{(\underbrace{2+\sqrt{2+\sqrt{\cdots+\sqrt{2+1}}}}_{\text {angka } 2 \text { sebanyak k suku }})^{\frac{3}{2}}}{8}
$$

(iii) Lebih lanjut, akan dibuktikan kebenaran untuk $n=k+1$, berlaku

$$
\left.\cos \left(\frac{\alpha}{2^{k+1}}\right) \cos \left(\frac{\beta}{2^{k+1}}\right) \cos \left(\frac{\gamma}{2^{k+1}}\right) \leq \frac{(\underbrace{2+\sqrt{2+\sqrt{\cdots+\sqrt{2+1}}}}_{\text {angka 2sebanyak } k+1 \text { suku }}}{8}\right)^{\frac{3}{2}}
$$

Misalkan $x=\cos \frac{\alpha}{2^{k+1}}, y=\cos \frac{\beta}{2^{k+1}}, z=\cos \frac{\gamma}{2^{k+1}}$. Dengan memanfaatkan ketaksamaan rerata aritmatika-geometri (Mineno et al., 2012), diperoleh

$$
\cos \left(\frac{\alpha}{2^{k+1}}\right) \cos \left(\frac{\beta}{2^{k+1}}\right) \cos \left(\frac{\gamma}{2^{k+1}}\right) \leq\left(\frac{\cos \left(\frac{\alpha}{2^{k+1}}\right)+\cos \left(\frac{\beta}{2^{k+1}}\right)+\cos \left(\frac{\gamma}{2^{k+1}}\right)}{3}\right)^{3}
$$

Berdasarkan Teorema 7, diperoleh

$$
\cos \left(\frac{\alpha}{2^{k+1}}\right) \cos \left(\frac{\beta}{2^{k+1}}\right) \cos \left(\frac{\gamma}{2^{k+1}}\right) \leq\left(\frac{\frac{3}{2} \sqrt{\text { angka } 2 \text { sebanyak } k+1 \text { suku }}}{3}\right)^{2+\sqrt{2+\sqrt{\cdots+\sqrt{2+1}}}}
$$

\section{Kesimpulan}

Berdasarkan hasil dan pembahasan dapat diperoleh ketaksamaan cosinus sudut-sudut segitiga sebagai berikut.

1. $1<\cos \alpha+\cos \beta+\cos \gamma \leq 3 / 2$

2. $0<\cos \alpha \cos \beta \cos \gamma \leq 1 / 8$

dengan $\alpha, \beta, \gamma$ menyatakan sudut-sudut segitiga.

Selanjutnya dari kedua ketaksamaan di atas dapat diperluas/ digeneralisasi menja- 
di :

1. $(\cos \alpha)^{2^{n}}+(\cos \beta)^{2^{n}}+(\cos \gamma)^{2^{n}} \geq \frac{3}{(2)^{2^{n}}}$

2. $\cos \left(\frac{\alpha}{2^{n}}\right)+\cos \left(\frac{\beta}{2^{n}}\right)+\cos \left(\frac{\gamma}{2^{n}}\right) \leq \frac{3}{2} \cdot \sqrt{\frac{2+\sqrt{2+\sqrt{\cdots+\sqrt{2+1}}}}{\text { angka } 2 \text { sebanyakn suku }}}$

3. $\left.\cos \left(\frac{\alpha}{2^{n}}\right) \cos \left(\frac{\beta}{2^{n}}\right) \cos \left(\frac{\gamma}{2^{n}}\right) \leq \frac{(\underbrace{2+\sqrt{2+\sqrt{\cdots+\sqrt{2+1}}}}_{\text {angka 2 sebanyaknsuku }}}{8}\right)^{\frac{3}{2}}$

untuk setiap $n$ bilangan asli.

\section{Ucapan Terimakasih}

Penulis ucapkan terima kasih kepada Universitas PGRI Argopuro Jember dan semua pihak yang berperan dalam pembuatan dan penulisan artikel ini.

\section{Daftar Pustaka}

Annaby, M., \& Hassan, H. (2018). Trigonometric sums by Hermite interpolations_ Applied Mathematics and Computation, 330, 213-224.

Ayres, F. (1954). Schaum's Outline Series Theory, and Problems of Plane, and Spherical Trigonometri. Mc Graw Hill Book Company.

Beveridge, R. W. (2014). Trigonometry. Creative Commons.

Bottema, O. (1969). Geometric Inequalities. Wolters Noordhoff Publishing.

Chauvenet, W. (1887). A treatise on plane, and spherical trigonometry. J B Lippincott Company.

Coghetto, R. (2014). Some Facts about Trigonometry, and Euclidean Geometry. Formalized Mathematics, 22(4), 313-319.

Conway, J., \& Ryba, A. (2016). Remembering Spherical Trigonometry , To appear in the Math Gazette , March 2016. March, 1-9.

Gonz, L. (2012). On the Intersections of the Incircle, and the Cevian Circumcircle of the Incenter. Forum Geometricorum, 12, 141-148.

Gresham, J., Wyatt, B., \& Crawford, J. (2019). Essential trigonometry without geometry. Texas J. of Sci, 71(1). 
Hoehn, L. (2013). Derivation of the law of cosines via the incircle. Forum Geometricorum, 13, 133-134.

Josefsson, M. (2011). The Area of the Diagonal Point Triangle. Forum Geometricorum, 11, 213-216.

Kamariah, K. (2015). Garis Istimewa Pada Segitiga. MAGISTRA: Jurnal Keguruan Dan Ilmu Pendidikan, 2(2), 205-212.

Mineno, K., Nakamura, Y., \& Ohwada, T. (2012). Characterization of the intermediate values of the triangle inequality. Mathematical Inequalities and Applications, 15(4), 1019-1035.

Nhi, D. A. M. V. A. N. (2013). A new inequality and identity. Journal of Science and Arts, $1(22)$.

Putri, L., Lopes, F., \& Fitriani, Y. (2020). Analisis Aplikasi Belajar Bentuk Dalam Upaya Mengenalkan Bentuk Geometri Pada Anak Usia 4-5 Tahun Analysis of Belajar Bentuk Applications in an Effort to Introduce Geometry Shapes to 4-5 Years Old Children Lucia Putri Frida Lopes. Kalimaya, 8, 1-10.

Sundstrom, Ted and Schlicker, S. (2021). Trigonometry. Creative Commons.

Surlina, S., Mashadi, M., \& ... (2018). Menentukan Panjang Jari-jari Lingkaran Sawayama-Thebault. Jurnal Sains Matematika Dan Statistika, 4(2), 37-44.

Zou, L., \& Jiang, Y. (2015). Improved arithmetic-geometric mean inequality, and its application. Journal of Mathematical Inequalities, 9(1), 107-111. 